\title{
O Instituto do Ceará e a intelectualidade cearense: Identidade regional, sociabilidade e escrita da história da abolição na província
}

\author{
DOI: 10.15175/1984-2503-201810306
}

\author{
Camila de Sousa Freire* \\ Ana Paula Barcelos Ribeiro da Silva*
}

\begin{abstract}
Resumo
Este trabalho objetiva analisar a formação de uma intelectualidade cearense entre o final do século XIX e as primeiras décadas do século $\mathrm{XX}$, bem como suas redes de sociabilidade e atuação, principalmente, no que diz respeito à escrita da história e à construção de uma identidade regional cearense. Entre outros locais de sociabilidade, destacamos a atuação destes homens no Instituto do Ceará e a divulgação de suas ideias através da Revista do Instituto. São enfatizados alguns aspectos que ganham projeção na identidade regional cearense, como a seca e um suposto caráter especial do cearense, por meio dos discursos desses intelectuais, assim como o movimento abolicionista, que culminou com a libertação dos escravos na província em 1884. Nesse sentido, sobretudo o pioneirismo na abolição foi consolidado pelo Instituto e se tornou marco fundamental em um processo de construção identitária que relaciona memória e história no olhar sobre o passado.
\end{abstract}

Palavras-chave: escrita da história; identidade regional; Instituto do Ceará; intelectuais cearenses.

\section{El Instituto do Ceará y el registro escrito de la abolición de la esclavitud}

\section{Resumen}

La finalidad de este trabajo es analizar la formación de la intelectualidad del estado de Ceará entre finales del siglo XIX y las primeras décadas del siglo XX, así como sus redes de sociabilidad y actuación, sobre todo en lo relativo al relato histórico de los hechos y a la construcción de una identidad regional de Ceará. Entre otros espacios de sociabilidad, destacamos la actuación de las personas del Instituto do Ceará (creado en 1897) y la divulgación de sus ideas a través de la propia revista del instituto. Se hace hincapié en algunos aspectos que adquieren proyección en el discurso sobre la identidad regional de Ceará, como la sequía y un supuesto carácter especial de los habitantes de este estado, además del movimiento abolicionista, que culminó con la liberación de los esclavos en la por aquel entonces provincia de Ceará en 1884. La iniciativa pionera de la abolición en Ceará fue consolidada por el instituto y se convirtió en marco fundamental del proceso de construcción identitaria que, al mirar al pasado, relaciona memoria e historia.

Palabras clave: relato histórico; identidad regional; Instituto do Ceará, intelectuales de Ceará.

\section{The Instituto do Ceará and the writing of the history of the Abolition of Slavery}

\section{Abstract}

The following work aims to analyze the shaping of the Brazilian state of Ceará's intellectuals from the end of the nineteenth century to the early decades of the twentieth century, as well as the group's sociability and

* Mestre em História Social pela Universidade do Estado do Rio de Janeiro - Faculdade de Formação de Professores. Graduada em História pela mesma universidade. E-mail: camilachristi@yahoo.com.br. Orcid ID: https://orcid.org/0000-0002-6096-0615

${ }^{*}$ Doutora em História Social pela Universidade Federal Fluminense. Professora Adjunta do Departamento de Ciências Humanas e do Programa de Pós-Graduação em História Social da Universidade do Estado do Rio de Janeiro - Faculdade de Formação de Professores. E-mail: anapaulabarcelos@gmail.com. Orcid ID: https://orcid.org/0000-0002-9625-1757 
activity networks, mainly in terms of the writing of history and the building of a regional identity for the state. Among other hubs of sociability, we highlight the men's activities at the Instituto do Ceará (created in 1897) and the publication of their ideas in the Institute Journal. We emphasize several aspects of the debate on the state's regional identity, such as drought and the supposedly special character of the locals, as well as the Abolitionist Movement, to have culminated in the release of the province's slaves in 1884. Ceará's pioneering position in the abolition of slavery was consolidated by the Institute, becoming a major milestone in a process to have shaped its identity by associating memory and history in its gaze toward the past.

Keywords: Writing of history; regional identity; Instituto do Ceará; Ceará intellectuals.

\section{L'Institut du Ceará et l'écriture de l'histoire de l'abolition de l'esclavage \\ Résumé}

Cet article a pour objectif d'analyser la formation de la scène intellectuelle de l'État du Ceará entre la fin du $\mathrm{XIX}{ }^{e}$ siècle et les premières décennies du $\mathrm{XX}^{\mathrm{e}}$, ainsi que ses réseaux de sociabilité et d'action, principalement en ce qui concerne l'écriture de l'histoire et la construction d'une identité régionale propre à cet État. Parmi les lieux de sociabilité, nous soulignerons le rôle des membres de l'Institut du Ceará (créé en 1897) et la diffusion de leurs idées par l'entremise de la revue de l'institut. Y sont mis en avant certains aspects récurrents du discours sur l'identité régionale du Ceará, comme la sécheresse et un supposé caractère spécifique de ses habitants, ou encore le mouvement abolitionniste, qui a culminé par la libération des esclaves de la province en 1884. Ce rôle de pionnier dans l'abolition de l'esclavage a été consolidé par I'Institut et est devenu un élément fondamental du processus de construction identitaire liant mémoire et histoire dans le regard porté sur le passé.

Mots-clés : écriture de l'histoire ; identité régionale ; Institut du Ceará ; intellectuels du Ceará.

\section{塞阿拉研究所和废除奴隶制历史的撰写 \\ 摘要}

本论文分析了十九世纪末至二十世纪头十年之间, 巴西北部塞阿拉地区知识分子的形成, 以及他们的社会交往 与活动的网络, 特别是他们对于历史的书写和塞阿拉的区域认同建设的贡献。除了其他的人文社交场所以外, 我们重点研究塞阿拉研究所(成立于1897年), 在该所工作与活动的主要知识分子和传播他们思想的研究所学 报。我们着重分析他们对塞阿拉地域认同建设具有重大意义的某些话语, 比如干旱和塞阿拉人的一个所谓的特 殊性格, 以及塞阿拉省的废奴运动--最终导致该省于1884年解放全省所有奴隶。塞阿拉在 1884 年开启的废奴实 践直接导致巴西全国的解放奴隶, 其中塞阿拉研究所的作用是非常之大。该研究所的先锋主义思想行为是塞阿 拉历史身份建构过程中的一个里程碑，它将记忆，历史与反思过去串联在一起。

关键词：历史书写, 区域认同，塞阿拉研究所，塞阿拉的知识分子。

\section{Introdução}

Fundado em 1887, o Instituto Histórico, Geográfico e Antropológico do Ceará atuou na escrita da história da então província, conferindo-Ihe um lugar na história nacional e contribuindo para a construção de uma identidade regional que tinha como foco o pioneirismo na abolição da escravidão e a força do cearense capaz de superar os obstáculos climáticos oriundos da seca. Ao mesmo tempo, funcionou como espaço de sociabilidade fundamental no qual os intelectuais cearenses formavam redes, trocavam ideias e afirmavam-se enquanto aqueles que possuíam legitimidade para falar da história da região. O Instituto foi criado como instituição congênere ao Instituto Histórico e Geográfico Brasileiro (IHGB), de caráter científico e cultural, com o objetivo de tornar conhecidas a História e a Geografia da província, bem como seus aspectos antropológicos. 
Studart, Júlio Cezar, Padre Frota, Antonio Augusto e Antonio Bezerra, homens abastados da capital cearense, entre os quais estavam políticos, médicos e jornalistas. Segundo seus estatutos, o objetivo da instituição era "tornar conhecidas a historia e geographia da Provincia e concorrer para o desenvolvimento das lettras e sciencias" (ESTATUTOS..., 1887, p. 9). ${ }^{a}$ Neste artigo, pensamos a escrita da história e a formação de uma identidade regional no Ceará a partir da sua fundação até a década de 1950, quando acreditamos que este processo esteja consolidado com a publicação da obra $A$ Abolição no Ceará, por Raimundo Girão (1956) - autor que acaba ganhando projeção na análise.

Apresentamos uma reflexão sobre quem escreve essa história de caráter regional com foco numa legitimação nacional, bem como questões referidas ao poder, às estratégias de ascensão profissional e às redes de sociabilidade constituídas por esses sujeitos. Com o auxílio de Pierre Bourdieu e Sérgio Miceli, buscamos compreender o peso do capital simbólico, das disputas no campo intelectual e da atuação em cargos públicos na leitura que produzem do passado e que se tornou referência para o olhar sobre o cearense em seus contextos e nas décadas posteriores. A análise possibilita ainda a ruptura com a linearidade na análise de trajetórias individuais ou de grupos e coletividades e com uma ideia de genialidade e vocação muito presentes na autoimagem divulgada por esses intelectuais e por seus pares e familiares. Tratamos, assim, de poder, conflito, estratégias e articulação política na escrita da história. Simultaneamente, Bourdieu nos auxilia a compreender as lutas regionais que caracterizam a construção de uma identidade (que se apropria da história) e o que possibilita que certos discursos se sobreponham a outros, que alguns sujeitos e instituições estejam autorizados a falar, como ocorre com o Instituto do Ceará e seus membros no período em tela. Com isso, acreditamos que este texto contribua para a ampliação do foco dos estudos sobre historiografia brasileira com uma análise acerca da intelectualidade cearense entre o final do século XIX e a primeira metade do século $X X$.

\section{Intelectuais cearenses e associações culturais no final do século XIX e nas primeiras décadas do século $X X$}

A segunda metade do século XIX foi de intensa movimentação intelectual na província do Ceará. Nesse período, a partir de um maior desenvolvimento econômico, surgiram também diversas agremiações literárias que congregavam homens que, após uma fase de estudos fora da província, retornavam com uma bagagem cultural que 
desejavam utilizar na interpretação da realidade de sua terra natal. É a trajetória desses homens e seu engajamento intelectual e social o fio condutor deste artigo.

Segundo Simone Souza e Frederico de Castro Neves (2015), ${ }^{a}$ intelectuais são aqueles que atuam na produção de ideias em determinado contexto; são homens e mulheres refletindo sobre seu tempo e expressando essa produção em forma intelectual ou artística, de modo a mobilizar seus contemporâneos a dela compartilhar. Essa produção demonstra a "capacidade de organização e diferenciação social de uma determinada sociedade" (SOUZA; NEVES, 2015, p. 14), b se expressando em livros, jornais, revistas, partidos políticos, instituições, entre outros. Angela de Castro Gomes (2013, Kindle, pos. 643), ${ }^{a}$ inspirada em Jean François Sirinelli, adota uma concepção de intelectual que o entende como "produtor de bens simbólicos envolvido direta ou indiretamente na arena política”. Para Sirinelli (2003, p. 231-269), , o estudo dos intelectuais deve basear-se numa noção ampla e sociocultural que englobe criadores e mediadores culturais. Apresentando objeções à concepção de campo e às estratégias analisadas por Bourdieu, defende a contingência, o inesperado e o fortuito. Destaca, assim, as afinidades, as afetividades e as sensibilidades ideológicas e culturais comuns. Isto sem deixar de inserir o intelectual em seu ambiente social e cultural. Aspectos dos quais compartilhamos, embora não sejam esses nossos focos nesse artigo, mas sim justamente as redes e estratégias esmiuçadas por Bourdieu.

Em Fortaleza, foi no final do século XIX que se desenvolveu de forma mais acentuada a atividade intelectual, fruto da expansão econômica na região e do contexto político do próprio país. Almir Leal de Oliveira $(2015)^{a}$ trata da formação desses intelectuais da década de 1870 desde o ensino secundário, com a criação das principais instituições de ensino de Fortaleza, que surgem na mesma época. Antes da criação do Liceu do Ceará (1845) e posteriormente do Ateneu Cearense (1863), apenas uma pequena parcela abastada podia concluir os estudos. Aqueles que desejavam o ensino superior deveriam buscar em outras regiões. Mas, com a criação desses colégios ampliou-se a educação na província, contribuindo para a formação de uma geração que iria influenciar nos acontecimentos políticos ou em movimentos intelectuais e sociais, como a fundação de agremiações e o próprio movimento abolicionista. Com o desenvolvimento da região, houve um aumento das linhas de navios a vapor e de seus trajetos entre o Ceará e outras províncias e para o exterior, ampliando as relações econômicas. Com isso, amplia-se também o número de produtos comercializados, entre eles livros, revistas e jornais, como, por exemplo, a Revue de Deux Mondes e os livros de Spencer, Taine, Buckle, Darwin, entre 
outros. Nesses mesmos vapores, chegavam ao Ceará os estudantes que retornavam à província após a conclusão do curso superior, como Antônio Bezerra de Menezes, que retorna em fins da década de 1860, após concluir o curso de Ciências Jurídicas e Sociais na Faculdade do Largo de São Francisco, em São Paulo. Assim como ele, outros estudantes chegavam trazendo as influências do ambiente intelectual de outras regiões. Para Almir Leal de Oliveira, a bagagem cultural adquirida por esses estudantes é muito importante, pois é a partir dela que poderão atuar em sua própria realidade.

Porém, na década de 1840, já havia sido fundado o Liceu do Ceará, oferecendo à elite cearense a formação chamada "preparatória", pois a partir dela o estudante estaria apto a cursar a faculdade. Antes disso, esta formação deveria ser buscada em Recife, Salvador ou na Corte. É importante destacar que havia uma lei que permitia ao Colégio Pedro II conceder o diploma de bacharel em Letras, dispensando assim a necessidade de se fazer exames de admissão nas academias, o que não havia nas províncias. No entanto, mesmo sem o diploma de bacharel em Letras, o Liceu do Ceará permitiu a "capacitação da elite local" (OLIVEIRA, 2015, p. 18), , estabelecendo dessa forma os "parâmetros intelectuais para uma possível atuação crítica, fosse ela política ou não" (OLIVEIRA, 2015, p. 18). ${ }^{c} \mathrm{O}$ fato de não conceder o diploma de bacharel em Letras era uma restrição, mas ainda assim, diante do contexto geral, o Liceu:

[...] ampliava a possibilidade de ingresso de membros da elite local nas academias e ampliaria também o nível de participação política provincial no universo da política imperial. Nesse sentido, a criação do Liceu do Ceará se inscreve em um processo mais amplo de constituição da própria elite dirigente local (OLIVEIRA, 2015, p. 19). ${ }^{d}$

O Liceu formaria ainda "um núcleo homogêneo de habilidades profissionais [...] a partir da concentração geográfica dos cursos, da concentração temática e especificidade dos currículos" (OLIVEIRA, 2015, p. 19). e Pelo fato de constituírem um pequeno grupo de letrados em um ambiente de amplo analfabetismo garantiram, então, "coesão ideológica ao grupo, fator essencial na formação da elite política" (OLIVEIRA, 2015, p. 19). Ainda assim, o curso oferecido pelo Liceu era em regime de seriado, em um período de cinco a seis anos, o que era considerado prolongado. Esses fatores acabaram contribuindo para 0 desenvolvimento de instituições particulares de ensino. Dentre estas, destacava-se o Atheneu Cearense, atuando a partir de 1863. Assim, estes estudantes provenientes de camadas mais abastadas da sociedade interagiram nesses espaços identificando-se entre si e desenvolvendo um olhar sobre a realidade social próprio desses espaços nos quais estavam inseridos. Esses contatos se materializariam nos movimentos intelectuais e políticos. Segundo o autor, nesses espaços os laços de classe eram reforçados através de 
práticas como obediência, disciplina, organização hierárquica e práticas culturais europeias. Essas práticas moldaram a "visão de mundo dessa geração a partir das leituras e experiências compartilhadas, que definiriam a atuação posterior desses intelectuais" (OLIVEIRA, 2015, p. 23). ${ }^{9}$

Nesse contexto, foi fundado, por estudantes de Fortaleza, em 1870, o primeiro grupo de estudos literários e científicos, chamado Fênix Estudantal. O grupo não durou, mas com o retorno de Capistrano de Abreu e Thomás Pompeu Filho à província em 1871 houve uma nova iniciativa nesse sentido, e fundou-se a Academia Francesa, o principal movimento intelectual cearense. O grupo se reunia para estudar, ler e debater o positivismo de Comte. Além disso, criou a Escola Popular, para organizar conferências noturnas para os trabalhadores. Esse grupo articulava-se com outros que atuavam naquele momento, como os maçons, que também apostariam na educação das classes populares como elemento de transformação social, levando à civilização desejada nos moldes do positivismo, principal influência teórica dos intelectuais do período. Para Oliveira (2015, p. 25), ${ }^{\text {h "a }}$ Academia pode assim ser entendida como um movimento intelectual com propostas de leituras, articulações políticas e intelectuais e uma ação educativa". Assim, a partir da valorização da objetividade do conhecimento científico "a relação natureza-homem passa a ser vista pela mesma ótica da objetividade" (OLIVEIRA, 2015, p. 25). ' Na década de 1870, evidentemente, surgiram movimentos intelectuais contestatórios também na Corte, como destaca Angela Alonso (2009). . A autora trabalha a chamada "Geração de 1870", composta por intelectuais brasileiros que se apropriaram de ideias estrangeiras buscando soluções de acordo com suas próprias experiências. Essa apropriação não criava teorias próprias, mas adaptava as já existentes, contestando determinadas situações vigentes na realidade social desses intelectuais. Nesse momento, o debate girava em torno da contestação da elite política imperial, da escravidão e da própria monarquia.

Alonso destaca o liberalismo estamental, onde o elemento relevante não era o indivíduo, mas a família, incluindo os escravos; o catolicismo hierárquico, herdado da metrópole e que permaneceu no Império; e o indianismo romântico, que trouxe os ímpetos revolucionários e o sentimentalismo sob forte influência da religiosidade (ALONSO, 2009,

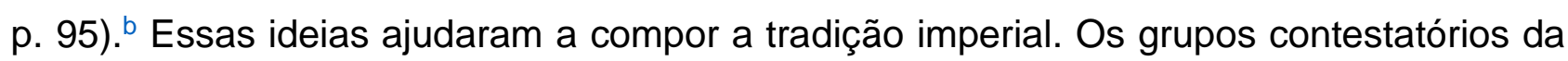
geração de 1870 buscaram outras teorias para criticar esta tradição. Esses intelectuais, no entanto, buscaram alguns elementos da tradição imperial e seus personagens, tais como o Romantismo, com Castro Alves; personagens como frei Caneca e Tiradentes; e movimentos como a Confederação do Equador (1824) e a Revolta Praieira (1848-1850). 
Sua produção constituiu-se em textos para debate público onde os temas eram 0 indianismo, o liberalismo, o catolicismo, a monarquia e a escravidão (ALONSO, 2009, p. 98). ${ }^{\mathrm{c}}$

Havia também diferentes grupos que buscavam reivindicar seus próprios interesses, pois se viam impedidos de participar das decisões políticas, como por exemplo os liberais republicanos, os federalistas positivistas e os positivistas abolicionistas. Esses grupos, mesmo com pautas diversas, tinham em comum a militância contra a escravidão. Todos viam a necessidade da abolição. Como autores lidos por estes intelectuais, Alonso (2009, p. 102) ${ }^{d}$ cita Stuart Mill, Comte e Pierre Laffitte. Assim, a geração de 1870 foi um movimento de contestação dos valores e instituições imperiais, onde cada grupo possuía suas pautas prioritárias. Porém, todos eles almejavam a abolição da escravidão, mesmo que divergindo quanto à forma como ela se daria. Para Alonso (2009, p. 111), ${ }^{e}$ este foi um movimento reformista, pois não pretendia alcançar seus objetivos por vias revolucionárias, e foi, ao mesmo tempo, um movimento social na medida em que orquestrou mobilizações coletivas. Buscou na Europa não apenas referências teóricas, mas meios de ação, principalmente na Inglaterra e na França, onde surgiam novos meios de ativismo político, como comícios, passeatas, entre outros - meios amplamente utilizados no Brasil, inclusive no movimento abolicionista (ALONSO, 2009, p. 112). ${ }^{\dagger}$

Foi nesse contexto que se moldou a influência do determinismo climático que iria predominar no discurso intelectual cearense da década de 1880 como base para 0 movimento abolicionista, a literatura e a própria identidade regional, a partir da entrada dessas novas teorias na realidade cearense. Oliveira (2015, p. 28)j diz que:

[...] o movimento que se originou nas atividades da Academia Francesa formou entre a camada letrada de Fortaleza vínculos de afinidades que mais tarde foram encontrados nos movimentos políticos da abolição dos escravos, bem como nos movimentos literários da década de 1880.

Dessa forma, vemos também as bases teóricas que agiram como motivação para que esses homens, posteriormente, se engajassem no movimento pela abolição dos escravos. Era o desejo de intervir na sociedade a fim de acelerar sua transformação rumo ao progresso, visto que a escravidão era tida como um obstáculo ao desenvolvimento da civilização; além de se colocarem como representantes da cientificidade nesse processo. No jornal Libertador, órgão da Sociedade Cearense Libertadora, a mais importante e atuante sociedade abolicionista do Ceará, fundada em 1880, encontramos essa noção de escravidão como atraso. Este aspecto fica claro desde o início, já no número 02, de 1881, quando se diz: "[...] é tempo que desapareça do meio de nós esta infâmia que retarda o 
nosso progresso e nos distancia do lugar que compete-nos no congresso das nações" (ABAIXO..., 15 jan. 1881, n. 2, p. 1). ${ }^{\text {a }}$

A Academia Francesa chegou ao fim em 1875, mas, no mesmo ano, alguns de seus antigos membros, em conjunto com outros estudantes fundaram o Gabinete de Leitura, com o objetivo de manter uma biblioteca e difundir as leituras cientificistas na província. A partir desta agremiação, outras foram surgindo, entre elas as literárias e abolicionistas da década de 1880. Neste período, segundo Almir Oliveira, entre os temas marcantes dos movimentos sociais no Ceará estavam a reorganização após a seca, a abolição, o movimento republicano e o desejo de inserir a província nas mudanças que trariam o progresso material típico da civilização europeia. Estes temas nortearam os debates entre os intelectuais principalmente na imprensa. Foram as influências teóricas da década de 1870 que marcaram essa geração e motivaram sua ação social. Assim, colocando-se:

Como arautos de um conhecimento pragmático, voltados para uma ação direta que indicaria o caminho da civilização e progresso social esperados para o Ceará, esses intelectuais se identificariam com determinadas "missões" como a abolição dos escravos, a escrita de uma narrativa científica para o Ceará, interferindo decisivamente na consolidação de um novo universo intelectual em Fortaleza (OLIVEIRA, 2015, p. 38).k

Segundo Gleudson Passos Cardoso (2015, p. 41), ${ }^{a}$ no Ceará, no momento de transição da Monarquia para a República, esses intelectuais atuaram em "jornais partidários, revistas científicas e periódicos literários", disseminando visões políticas e científicas do que deveria ser a nova nação. Nesse contexto, a imprensa local se dividia em duas frentes: o jornalismo político e o literário/científico. Assim, defendiam seus princípios filosóficos e atuavam na opinião pública, informando-a dos debates políticos e intelectuais da época. Estes se baseavam em sua vivência cotidiana, em sua origem social, nas leituras que faziam; uns se fascinando com as transformações da época, outros as temendo. Dividiram-se em duas gerações. Uma foi a Mocidade Cearense, composta por aqueles que participaram dos movimentos pelo "racionalismo filosófico" (CARDOSO, 2015, p. 44) e pela abolição, entre 1870 e 1880, na Academia Francesa, na Sociedade Cearense Libertadora, no Centro Abolicionista e no Clube Literário. Parte destes fundou o Instituto do Ceará, a Academia Cearense e o Centro Literário. A segunda geração foram os Novos do Ceará, inspirados no movimento abolicionista, composta por camponeses e imigrantes e pelas classes populares; foram inspirados também pelas ideias democráticas e republicanas e fundaram a Padaria Espiritual e o Centro Literário. A origem social dos componentes da Mocidade era, em sua maioria, das classes abastadas, com poder na política local, e também de camadas médias que emergiam com o desenvolvimento algodoeiro. Uma 
exceção seria Justiniano de Serpa, de origem popular, mas que acabou por aproximar-se dos grupos políticos oligárquicos. A Academia Francesa, então, foi uma iniciativa da Mocidade, que procurou se engajar nas questões políticas e sociais nas décadas de 1870 e 1880. Sobre a atuação da Mocidade no movimento abolicionista, Cardoso $\left(2015\right.$, p. 48) ${ }^{c}$ diz:

Na década de 1880, a Mocidade Cearense encabeçou os debates em torno da abolição da escravatura no espaço do Clube Literário, uma ramificação do movimento abolicionista (Sociedade Cearense Libertadora e seu jornal $O$ Libertador) e da então extinta Academia Francesa. Com sua revista A Quinzena (1887), alguns escritores como Rodolfo Teófilo, Paulino Nogueira, João Lopes, Antônio Martins, Oliveira Paiva, Justiniano de Serpa, Antônio Bezerra, Guilherme Studart, Abel Garcia, dentre outros, publicaram artigos pelo órgão que teve repercussão local e nacional. Eles justificaram com a filosofia evolucionista a abolição do cativeiro na província do Ceará (em 1884, quatro anos antes da emancipação no restante do Brasil). Em geral, refletiram que o fato foi resultado da evolução biológico-social-moral do povo cearense, por adaptar-se à ação violenta das forças mesológicas e climáticas (referindo-se à seca de 1877/1879), teria adquirido força e índole capazes de promover o bem-comum [...].

É possível perceber, então, que os mesmos intelectuais agiam em várias agremiações, como é o caso dos citados por Cardoso, reunindo-se na Sociedade Cearense Libertadora e no Clube Literário e escrevendo no jornal Libertador e, posteriormente, na revista $A$ Quinzena. Alguns iriam também participar da fundação do Instituto do Ceará e escrever em sua revista, como Paulino Nogueira, Guilherme Studart e Antônio Bezerra, que participaram de sua fundação, e João Lopes, Abel Garcia, Justiniano de Serpa, entre outros, que escreveram na Revista do Instituto do Ceará. Vemos que os mesmos homens participaram de diferentes movimentos intelectuais naquela província e assim disseminavam suas ideias por diversos meios. Já na década de 1890, no momento de organização do novo regime, a Mocidade cria duas novas agremiações, ambas em 1894: a Academia Cearense, que tinha como órgão a Revista da Academia Cearense (18941922), possuindo o mesmo pensamento cientificista e evolucionista; e o Centro Literário, que através da revista Iracema (1895-1900) declarava apoio ao governo republicano. Nesse novo contexto histórico, esses intelectuais atuaram na sociedade visando legitimar seus interesses e dos grupos dominantes aos quais se vinculavam.

Destacando os Novos do Ceará, já na década de 1890, percebemos que seus membros tinham origem nas classes populares urbanas e do interior. Fundaram o Centro Republicano Cearense, onde iniciaram a carreira pública. Com eles, surgiram novas posturas diante das transformações sociais do período, oscilando entre aqueles que acreditavam nos ideais civilizatórios em voga; aqueles que desejavam preservar as tradições e costumes regionais e aqueles que se ressentiam com os resultados das 
mudanças e ideias difundidas pela Mocidade. Dentre os Novos do Ceará, uma parte fundou o Centro Literário e outra parte a Padaria Espiritual. Essas associações, em um momento de redefinição do regime político e de reorganização das oligarquias locais, na passagem na Monarquia para a República, buscaram legitimar o que seriam os elementos genuinamente regionais e nacionais entre a cultura popular. No que se refere aos intelectuais do Instituto do Ceará percebemos que em sua maioria eram bacharéis em Direito e haviam feito seus estudos preparatórios no Liceu do Ceará e, em seguida, na Faculdade de Direito do Ceará, o que demonstra a continuidade de um grupo que se constituía na escola primária e que construiu uma trajetória política e intelectual semelhante. A maioria também galgou altos cargos na burocracia daquele Estado, seja por nomeação ou concurso, além de atuar na imprensa. Eram ligados a diversas instituições literárias ou históricas além do Instituto do Ceará, como a Academia Cearense de Letras.

\title{
A elite intelectual: carreira, cargos públicos e disputas regionalistas
}

Segundo Sérgio Miceli (2001), ${ }^{a}$ que tem seu estudo focado no Sudeste, aqueles intelectuais que desenvolviam suas carreiras nos cargos públicos, ligados ao governo, também eram em sua maioria formados nessas profissões. Para Miceli (2001, p. 203), ${ }^{\mathrm{b}} \mathrm{o}$ capital social era o principal "trunfo" para ingressar no funcionalismo público. Porém, ao falar de si mesmos, ou em falas sobre eles, será defendida uma ideia de que possuíam uma vocação inerente para a vida intelectual; ou buscavam desconectar a produção intelectual do trabalho público:

\begin{abstract}
Enquanto alguns deles sujeitaram seus escritos às exigências postas pelos encargos da convocação política que os trouxe ao convívio com os núcleos executivos, outros procuraram resguardar uma parte de sua produção intelectual das injunções partidárias e das demandas que lhes faziam certas facções com que colaboravam. Todos eles, contudo, acabaram se tornando modelos de excelência social da classe dirigente da época à medida que suas obras se convertem em paradigmas do pensamento político do país (MICELI, 2001, p. 210). ${ }^{\circ}$
\end{abstract}

No Ceará, ao mesmo tempo em que publicavam obras sobre a província, atendendo a uma demanda da época de tornar conhecidos seus diversos aspectos e serem reconhecidos como referências sobre o assunto, publicavam também obras de poesias, crônicas e memórias. Assim, eles atuavam em várias frentes, sendo conhecidos pela versatilidade. Como destaca Miceli (2001, p. 210), "o traço mais característico da contribuição dessa elite intelectual e burocrática reside nas diversas frentes em que se desdobrava sua atuação política e cultural"; além das "recompensas" simbólicas que conseguiam, em forma de reconhecimento, como eleições para Academias - no Ceará, 
principalmente o Instituto do Ceará e a Academia Cearense de Letras - ou até medalhas, honrarias e monumentos em sua homenagem. A intelectualidade aqui destacada acabou por se dedicar, sobretudo, a escrever a história do Ceará. Nesse processo, se diziam levados para a carreira de escritores e intelectuais por uma inclinação inata, por possuírem vocação para tanto. Miceli (2001, p. 83) diz que até mesmo sem perceber esses homens “buscam justificar sua 'vocação', ou melhor, se empenham em reconstituir as circunstâncias sociais que, no seu entender, se colocam na raiz de suas inclinações para as profissões intelectuais".

Para Pierre Bourdieu (2007, p. 185), ${ }^{a}$ isto se dá por se exercer um culto romântico da biografia, que parte de um "sistema ideológico" no qual está inserida a concepção de "criação" como intrínseca ao artista/escritor; ou por uma visão "utópica" do intelectual, fundamentada em uma "aristocracia da inteligência". Ou seja, a ideia de homens dotados desde sempre de uma inteligência superior para a criação, que seria inerente à sua personalidade. Bourdieu, então, faz uma crítica às análises que não inserem a obra ou o autor em um contexto, pois acabam revestidos de uma originalidade que leva à reverência. Em sua opinião, para que a compreensão se faça, autor e obra devem ser inseridos no "campo ideológico de que fazem parte" e que demonstra "a posição de uma categoria particular de escritores na estrutura do campo intelectual, por sua vez incluído em um tipo

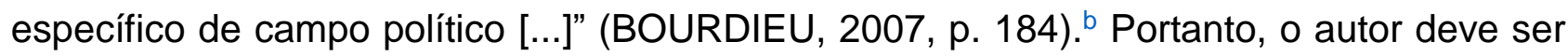
inserido em um campo próprio, o intelectual, que por sua vez deve ser inserido no campo político, pois ambos estão diretamente relacionados, como percebemos através dos ganhos materiais e simbólicos que estes homens conseguem com a inserção nesses campos.

Assim, é importante perceber a relação estabelecida entre os intelectuais em seu grupo e as diferentes frações da classe dominante. Relações que geralmente são ora de aproximação, ora de afastamento. É a partir das relações que cada categoria estabelece com o mercado e suas gratificações que se estabelece o grau de permanência ou exclusão, e, ao mesmo tempo, a experiência sobre a relação entre os artistas e as frações dominantes. Porém, o colocar-se como representante de uma classe não impede o trânsito por outras. É o que ocorre com Antônio Sales, por exemplo, pois o fato de criticar a elite política de Fortaleza não o impede de aceitar cargos públicos durante a implantação do regime republicano no Ceará. Portanto, segundo Bourdieu, para explicar a ordem que se estabelece entre as posições oferecidas pelo campo e aqueles que as ocupam não é possível recorrer à vocação, pois o que há são possibilidades e oportunidades oferecidas 
pelo campo no qual se está inserido. Na verdade, aquilo que se toma por vocação, ou "tomada de consciência" (BOURDIEU, 2007, p. 201), ${ }^{c}$ é o habitus. Assim, não se deve perder de vista a história de vida, mas situá-la, deixando claro que o indivíduo fez escolhas e que os acontecimentos não se deram de forma ordenada e linear em sua vida, apesar desses intelectuais se esforçarem em construir uma autoimagem baseada na genialidade, na vocação, na dedicação e no amor ao trabalho intelectual e na linearidade da trajetória. Há, assim, um perfil de intelectual que é moldado por esses homens e seus pares, caracterizado pela aliança entre inteligência superior e trabalho obstinado. Raimundo Girão (1900-1988) é um exemplo emblemático nesse sentido. O consideramos como aquele que consolidou a abolição no Ceará em 1884 como marco fundamental da identidade regional cearense através do seu livro A Abolição no Ceará, cuja primeira edição data de 1956. Girão estudou no Liceu do Ceará e posteriormente tornou-se bacharel em Direito, e desde então sua carreira deslanchou, ocupando diversos cargos públicos de prestígio em Fortaleza. Assim, passou a fazer parte da rede de sociabilidade política e intelectual daquela sociedade.

Ao analisarmos as falas de familiares e amigos de Girão, vemos novamente a ideia de vocação presente e a intenção de se criar uma trajetória linear e determinada, além da imagem de integridade na vida pública e privada. Geraldo da Silva Nobre já expressa a ideia no título de um artigo escrito sobre Girão: "Vocação e formação de um historiador". Nele diz que Girão teria uma inteligência privilegiada, assim como aqueles para os quais "os estudos históricos são mais viáveis [sendo um dos motivos a] tradição de interesse relativo ao passado, expressa na continuidade das várias gerações de historiadores cearenses" (NOBRE, 1988, p. 1), ${ }^{a}$ como Tristão Araripe, Senador Pompeu, João Brígido, Antônio Bezerra, Barão de Studart, entre outros. Seriam homens vocacionados para o trabalho intelectual e para a pesquisa histórica. Além da ideia de vocação, esses homens, e Girão especialmente, teriam o diferencial da dedicação e do amor ao trabalho intelectual. Eles se dedicariam com amor e afinco a esse trabalho e seu resultado transformaria a sociedade e os tornaria conhecidos para a posteridade. Qualidades inerentes a eles, algo natural, como vemos em um trecho de apresentação das obras de Girão em seu site, organizado por sua família:

Em estilo claro, simples e elegante, expressava os conceitos e ideias que lhe iam jorrando da pena, com uma naturalidade que revela o pleno conhecimento da língua portuguesa. Com igual naturalidade, manejava a escrita nos diversos níveis de erudição necessários às circunstâncias e às complexidades dos assuntos enfocados (APRESENTAÇÃO..., (C2011, par. 2). ${ }^{a}$ 
Seu neto Eurípedes Chaves Júnior, embora não use o sobrenome do avô, se encarregou de ser seu biógrafo, assim como outros membros da família escreveram sobre ele, em jornais, revistas e no próprio livro de Chaves Jr (2000). ${ }^{a}$ O que se percebe é que a família se dedicou a conservar e perpetuar sua memória, criando essa trajetória linear e coerente da qual já falamos. Com isso, acreditamos que esses sujeitos puderam mobilizar o capital simbólico que seu nome acionava naquela sociedade. Além disso, família e amigos buscaram demonstrar como Girão era um exemplo de homem público, um "arquétipo de cearense" (MACEDO, 1988, p. 1); a além de um exemplo de pai, esposo e avô.

Segundo Mozart Soriano Aderaldo (1988, p.1), ${ }^{a}$ ele era um homem de "múltiplas facetas [e um grande homem em todas elas]: ótimo filho, ótimo marido, ótimo pai, ótimo avô, ótimo irmão, ótimo amigo". Bourdieu (2006, pos. 3727, grifo do autor) ${ }^{\mathrm{a}}$ diz que no relato de vida, o objeto desse discurso é "a apresentação pública, [que é na verdade] a oficialização de uma representação privada de sua própria vida". Na verdade, acaba-se por mesclar essas duas esferas da vida do sujeito. Ao buscar um relato coerente entre o homem público e o privado, onde ele deve ser um exemplo nas duas esferas, a representação da vida privada no espaço público torna-se a própria vida pública, e vice-versa. Além de uma trajetória una, sem percalços, o sujeito passa também a ter uma personalidade una, sem defeitos. É o que percebemos na representação da trajetória de Raimundo Girão encontrada nesses relatos. Acreditamos então que se trata de um trabalho de enquadramento da memória, que, segundo Michael Pollak (1992), a é caracterizado por memórias políticas constituídas, enquadradas de acordo com determinados fins. Neste caso, busca-se formar uma imagem irretocável de determinada personalidade. Além disso, a memória é um elemento essencial de construção da identidade, seja coletiva ou individual. A imagem que vemos ser construída de Raimundo Girão é irrepreensível em todos os aspectos, no público e no privado, na construção de uma identidade de político e funcionário público, intelectual e historiador, que contribuiria para a formação da própria identidade regional cearense, através de sua produção.

Bourdieu também entende que o papel dos intelectuais nas disputas regionalistas deve ser situado tanto no local quanto no nacional, de acordo com os ganhos simbólicos ou econômicos que buscam alcançar. Para ele, estes intelectuais são aqueles que sofrem a dominação, logo calculam que seus ganhos serão maiores no âmbito regional, por ali haver menor concorrência. Já aqueles pertencentes aos dominantes, buscam mais o âmbito nacional, local do poder central, onde se encontra seu capital econômico e cultural. Ou ainda, saem de seus locais de origem e vão para o lugar central, em busca desse capital 
econômico e cultural, como José de Alencar, Capistrano de Abreu e Antônio Sales, no caso do Ceará. Bourdieu também nos esclarece sobre como algumas instituições possuíam os meios para legitimar determinados discursos, inseridas na luta pela identidade regional (BOURDIEU, 1989). ${ }^{\text {a }}$ Segundo ele, nessas lutas são desejados os meios de divisão pelos quais se formam e se reconhecem os grupos. Essa divisão legítima consiste no "ato de autoridade" de "circunscrever a região, o território" e de "impor a definição [...] legítima, conhecida e reconhecida, das fronteiras e do território, em suma, o princípio de divisão legítima do mundo social” (BOURDIEU, 1989, p. 104). ${ }^{b}$ Nas lutas regionais, os grupos são estigmatizados e essas divisões territoriais e sociais são arbitrárias, impostas por aqueles que possuem "autoridade", que consiste em se afirmar uma verdade, que gera reconhecimento, produzindo "a existência daquilo que se enuncia" (BOURDIEU, 1989, p. 114). ${ }^{c}$ Assim, aqueles que possuem autoridade determinam essas características para a região ao afirmar "com autoridade, quer dizer, à vista de todos e em nome de todos, publicamente e oficialmente, ele subtrai-as ao arbitrário, sanciona-as, santifica-as, consagra-as, fazendo-as existir como dignas de existir, como conformes à natureza das coisas [...]" (BOURDIEU, 1989, p. 114). ${ }^{d}$ É justamente essa autoridade que propicia a enunciação de discursos legítimos que os grupos regionais buscam subverter e tomar pra si, para poder caracterizar sua própria identidade.

Ele fala ainda sobre o discurso regionalista, que diz ser performativo, ou seja, tem em vista "impor como legítima uma nova definição de fronteiras e dar a conhecer e fazer reconhecer a região assim delimitada" (BOURDIEU, 1989, p. 114, grifo do autor), ${ }^{\mathrm{e}}$ em oposição a uma definição dominante já existente. A eficácia do discurso performativo consiste na autoridade de quem o enuncia. $O$ discurso produz o que está enunciando, mas quem anuncia deve estar imbuído de autoridade para tanto, ou seja, deve estar "autorizado a autorizar" (BOURDIEU, 1989, p. 114). ${ }^{\dagger}$ Consiste também em o discurso estar fundamentado na objetividade do grupo, ou seja, no reconhecimento e na crença que lhe conferem os membros do grupo, bem como nas características econômicas e culturais que têm em comum. Logo, o poder exercido sobre o grupo, que segundo Bourdieu (1989, p. 117) "se trata de trazer à existência enquanto grupo [é ao mesmo tempo o poder de impor princípios de visão e divisão comuns, ou seja] uma visão única da sua identidade, uma visão idêntica da sua unidade", a partir do discurso oficial. A oficialização tem sua realização completa na manifestação, onde o grupo marginalizado se torna visível para os outros e para si próprio "atestando assim a sua existência como grupo conhecido e reconhecido, que aspira a institucionalização" (BOURDIEU, 1989, p. 118). ${ }^{h}$ É o que buscavam os 
intelectuais reunidos no Instituto do Ceará, a partir de sua posição como instituição reconhecida para emitir discursos científicos.

Aqui é importante destacar também a abordagem do autor sobre o papel do discurso científico para legitimar determinadas classificações. É interessante observar o Instituto do Ceará sob esse prisma, como um lugar de autoridade para emitir discursos científicos, já que estes são importantes para atrair o reconhecimento para a região e sua história. Segundo Bourdieu (1989, p. 120, grifo no original), ' "qualquer enunciado sobre a região funciona como um argumento que contribui - tanto mais largamente quanto mais largamente é reconhecido - para favorecer ou desfavorecer o acesso da região ao reconhecimento e por este meio à existência". Para o autor, o regionalismo (como também o nacionalismo) é um caso particular das lutas simbólicas onde os agentes podem estar envolvidos tanto individualmente (em dispersão) quanto coletivamente (organização). que está em jogo é a conservação ou transformação das "relações de força simbólicas e das vantagens correlativas, tanto econômicas como simbólicas [...]" (BOURDIEU, 1989, p. 124). ${ }^{j}$ Colocadas também como lutas pelos critérios de avaliação legítima, ou lutas de classificação, onde os agentes "empenham interesses poderosos, vitais por vezes" (BOURDIEU, 1989, p. 124), ${ }^{\mathrm{k}}$ na medida em que o valor da pessoa está reduzido à sua identidade social. Assim, nas lutas regionais, os agentes colocam toda sua vitalidade, todo seu "ser social [...] tudo o que define a ideia que eles têm de si próprios" (BOURDIEU, 1989, p. 124);' o que para eles constitui o "nós" em oposição aos "outros", e ao que se encontram ligados "por uma adesão quase corporal" (BOURDIEU, 1989, p. 124). ${ }^{\mathrm{m}}$ Isso, para ele, explica "a força mobilizadora excepcional de tudo o que toca à identidade" (BOURDIEU, 1989, p. 124). ${ }^{n}$

Assim, a luta regional teria como objetivo a "reapropriação coletiva deste poder sobre os princípios de construção e de avaliação da sua própria identidade [...]" (BOURDIEU, 1989, p. 125). ${ }^{\circ}$ Para tanto, eles se utilizam até mesmo dos estigmas que lhes são impostos em seus discursos por reconhecimento. O estigma confere as determinantes simbólicas e seus "fundamentos econômicos e sociais [que se tornam os] princípios de unificação do grupo e pontos de apoio objetivos da ação de mobilização" (BOURDIEU, 1989, p. 125). ${ }^{p}$ É o que também vemos no discurso do Instituto do Ceará, que utiliza o estigma de província pobre, castigada pelas secas, para obter reconhecimento na medida em que, apesar dessas características adversas do meio, consegue um feito considerado glorioso como ser a primeira província do Brasil a libertar todos os escravos. A luta regionalista seria também uma "resposta à estigmatização que produz o território" (BOURDIEU, 1989, p. 126).9 Se a 
região não fosse um "espaço estigmatizado", ou seja, uma província definida pela distância econômica e social em relação ao centro, privada do capital material e simbólico, que se concentra também no centro, não poderia reivindicar uma existência. Aqueles que fazem parte da região estigmatizada lutam justamente porque esta "existe como unidade negativamente definida pela dominação simbólica e econômica [...]" (BOURDIEU, 1989, p. 126). ' É para romper com essa definição e inverter as características estigmatizadas que a revolta contra essa dominação toma a "forma de reivindicação regionalista" (BOURDIEU,

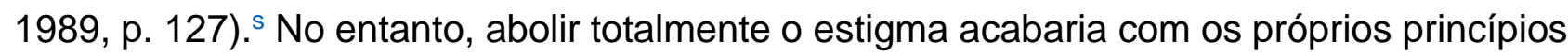
do "jogo", que leva à reivindicação pela existência. A luta regionalista busca reconhecimento a partir da afirmação do próprio estigma e sem este não haveria busca pela afirmação da existência. Este é o paradigma que Bourdieu aponta. Acreditamos, então, que o Instituto do Ceará busca subverter o discurso de autoridade definido pelo centro, que seria o Rio de Janeiro, então corte do Império, e legitimar seu próprio discurso, alcançando reconhecimento para sua região, como órgão científico com autoridade em âmbito regional.

Anne-Marie Thiesse $(1995)^{a}$ também se propõe a pensar o regionalismo, porém a partir do exemplo da França durante a Terceira República (1870-1940). A autora procura demonstrar como, naquele contexto, o regionalismo foi utilizado para demonstrar ao mesmo tempo a diversidade e a união da França - a diversidade compunha a nacionalidade. Assim, o regionalismo não teria sido construído em oposição ao nacional, mas para corrigir o centralismo excessivo em Paris, que começou a ser contestado em meados do século XIX. Dessa forma, Thiesse $\left(1995\right.$, p. 5) ${ }^{\text {b }}$ destaca que "o regionalismo, portanto, desempenha na história francesa um papel de consolidação da identidade nacional, relegado com frequência ao segundo plano, mas subitamente colocado em evidência nos períodos de crise intensa". Crise que naquele momento tinha como principais motivos este centralismo político e econômico em Paris, visto como um desequilíbrio; e a derrota francesa para a Alemanha na Guerra Franco-prussiana em 1870, que levou dirigentes e intelectuais a buscarem novos elementos que demonstrassem a excelência francesa. Essa grandeza consistia em sua diversidade, que fazia da França um país "abençoado pela natureza [e] o resumo ideal de toda a Europa" (THIESSE, 1995, p. 6). ${ }^{c}$ Assim, o patriotismo consistia em "conhecer, amar e avivar" (THIESSE, 1995, p. 7) d a diversidade francesa. Ela destaca que a escola teria importante papel neste sentido, já que era ali que as crianças primeiramente aprendiam sobre a "pequena pátria", a região, para depois aprenderem sobre a "grande pátria", a nação, onde a região estaria inserida, contribuindo para a sua unidade. Ela destaca o surgimento de Sociedades Regionalistas a partir do início do século XX, como 
museus de folclore, festivais de danças folclóricas e uma importante produção literária regionalista, de grande êxito entre o público, entre os anos de 1900 e 1930. Ela cita ainda a Exposição Internacional de Artes e Técnicas, realizada em Paris em 1937, onde os países tiveram oportunidade de expressar sua identidade nacional e seus projetos políticos, tendo a França, como tema de sua seção, o regionalismo.

Desse modo, a autora nos mostra como na França o regionalismo atuou fortemente como elemento de consenso da consciência nacional, sendo utilizado no sentido de união. Apresentava-se ainda como agente da paz social e superação dos conflitos, sendo utilizado em momentos de crise, onde cada região possuía sua identidade própria, iguais em direitos, que se complementavam no todo nacional. O que não foi diferente do que aconteceu no Brasil, como objetivamos demonstrar, onde buscava-se uma homogeneidade diante da diversidade do país. No que diz respeito à escrita da história, que é nosso foco principal, vemos como o IHGB buscou essa homogeneidade destacando a história das regiões para fortalecer a história e a identidade nacionais, seu principal objetivo diante das diversidades regionais. Por outro lado, as regiões, ao mesmo tempo em que contribuíam para o nacional, fortaleciam suas próprias identidades, como no caso do Ceará. O Instituto do Ceará, dessa forma, a partir da relação com o IHGB, caracterizada por trocas e pela fluidez, produz um discurso, imbuído de autoridade científica, que legitima a identidade regional no Ceará, utilizando-se do estigma das secas para forjar uma ideia de povo cearense e do pioneirismo da abolição.

Para Albuquerque Junior (2011, p. 63), ${ }^{a}$ o "intelectual regionalista quase sempre é aquele que se sente longe do centro irradiador de poder e de cultura. Ele faz da denúncia dessa distância, dessa carência de poder, dessa vitimização, o motivo de seu discurso", seja fazendo essa denúncia a partir da própria região ou partindo para a região central. No contexto analisado, no momento em que se pretende criar um novo olhar sobre o Nordeste e de desenvolvimento do romance regionalista, estes intelectuais cearenses se empenham na escrita da história de sua província, denunciando a distância do poder central e a carência de um interesse deste poder por sua história e, ao mesmo tempo, se colocando como aqueles que preencheriam essa lacuna a partir de seus trabalhos. Nesse sentido, 0 Instituto do Ceará era um local de indiscutível importância, pois como vemos, era considerado por eles como a maior sociedade intelectual do Ceará. Foi ali que estes homens se reuniram e dialogaram em torno de um objetivo comum: tornar conhecida a história do Ceará. 


\section{Os intelectuais e a abolição da escravidão na Revista do Instituto do Ceará}

O Instituto do Ceará seguiu as mesmas características do IHGB, de valorização do documento como indicador da verdade histórica, que legitimaria a nacionalidade. Foi fundado em um contexto onde, visto de forma mais ampla, no Brasil no século XIX, agremiações como esta eram caracterizadas por práticas intelectuais e políticas através das quais buscavam interferir em seu meio social. Acreditamos, assim, que tenha se tornado uma instituição chave que legitimaria a identidade regional cearense utilizando-se amplamente da memória em torno da abolição dos escravos na escrita da história da província, conferindo-Ihe caráter de verdade. Cardoso (2000, p. 10)a defende que houve nesses espaços letrados a construção de um "ideário ilustrado cearense para o Estado e Nação brasileiros diante da transição política". Ideário fundamentado em três bases: a chegada das "Luzes" e as ideias eurocêntricas que norteavam o progresso rumo à civilização, que conquistavam espaço entre os intelectuais cearenses naquele período; as secas, que foram interpretadas como uma fase evolutiva, dentro dos conceitos evolucionistas também em voga entre os intelectuais; e a libertação dos escravos em 1884, tida pelos intelectuais da Mocidade Cearense ${ }^{1}$ como uma conquista institucional perante o restante do país.

Assim, cria-se a imagem do cearense forte, que supera todas as adversidades do meio e que apesar das dificuldades ainda se preocupou com seus semelhantes, no caso os cativos, possuindo, por isso, uma personalidade especial (CARDOSO, 2000, p. 12). ${ }^{\mathrm{b}}$ Imagem esta que foi fortalecida pelo Instituto do Ceará, como se pode constatar em seus artigos que tratam da abolição, onde se afirma que logo depois da seca de 1877 a 1879, após muito sofrimento, o cearense teria se engajado na luta pela libertação dos escravos, mostrando suas supostas abnegação e coragem. Cardoso aborda ainda as questões políticas que ocorreriam no Ceará naquele momento de transição pelo qual o país passava, onde as oligarquias que então detinham o poder político buscavam meios de se adaptar aos novos rumos do país. Esses órgãos literários teriam servido a esses objetivos na medida em que, através de sua produção, buscavam inserir a população no novo contexto que se formava, fazendo crer que o país adentrava na modernidade, alcançando finalmente a civilização e o progresso, ideais caros à República - tarefa da qual também se incumbiu a imprensa.

\footnotetext{
${ }^{1}$ Movimento letrado ocorrido no Ceará na década de 1870 e que deu origem a agremiações, clubes e
} sociedades literárias. 
Nesse sentido, vemos a criação dos institutos regionais como uma tentativa de aumentar a contribuição regional para a história do país. No entanto, essas contribuições seriam remetidas ao IHGB, o centro que se encarregaria de construir a narrativa da nação. Assim, essa relação se caracteriza por um movimento de trocas constantes, em uma via de mão dupla, já que estes intelectuais dos institutos regionais viam nesta aproximação uma oportunidade de afirmação. De um lado, o Ceará contaria sua história para o restante do país; de outro, o IHGB buscava a unidade e a participação da província na história nacional, obtendo ainda documentos e publicações para seu acervo. Assim, acreditamos que a relação entre os dois Institutos se caracterize pela fluidez e reciprocidade, que marcam as relações entre centro e periferia, segundo analisa Ginzburg (1989), ${ }^{a}$ onde o Instituto do Ceará tentava demonstrar, a partir de documentos, que houve muitos episódios e personagens importantes para a história do Brasil no Ceará, como a abolição dos escravos em 1884, por exemplo. Os intelectuais do Instituto buscaram, então, romper com o estigma do atraso a partir do pioneirismo na abolição.

Portanto, procuramos entender, a partir da Revista do Instituto do Ceará, como o Instituto fortaleceu a identidade regional a partir da memória da libertação dos escravos naquela província em 1884, em um trabalho de escrita de uma história regional que contribuía para a história nacional. Dessa forma, esses intelectuais fundamentaram 0 discurso de que o Ceará seria um exemplo para o país, por ser uma terra de trabalho livre, pioneira na libertação dos escravos, a primeira província a abolir a escravidão já em 1884, possuindo um povo forte, resistente às intempéries do meio e abnegado por natureza. Vemos estes aspectos em um trecho do artigo da Revista do Instituto do Ceará intitulado "Uma data cearense", de Alba Valdez, publicado em 1984 por ocasião da comemoração dos cem anos da abolição no Ceará:

O povo cearense não podia supportar o innominavel trafico que rebaixava parte de seus semelhantes ao nível de alimarias. Envergonhava-o o espetaculo degradante da escravidão [...].

E o mesmo dinheiro, producto do braço escravo, queimava-Ihe as mãos válidas e honradas, afigurando-se-lhe criminosa extorção.

Pois elle sabia trabalhar, combater pela vida. Sua enfribatura mais de uma ocasião fôra posta à prova: em momento histórico, para defender os brios da Pátria, nos banhados mortiferos do Paraguay; todos os dias, nas florestas virgens da Amazonia, onde os perigos enxameiam no próprio ar.

Nascido sob o céo mais ingrato do Brasil, o cearense nunca foi um predilecto da fortuna. [...]

A actividade que o caracteriza tem albaroado contra frequentes caprichos da natureza. D'ahi talvez, sua indole afoita e generosa. 
Passagens. Revista Internacional de História Política e Cultura Jurídica

Rio de Janeiro: vol. 10, n⿳3, setembro-dezembro, 2018, p. 440-463.

Familiarizado desde cedo com a adversidade, sciente de quanto um minuto de amargura entoxica uma existencia inteira, desolava-o a excrescencia abjecta do captiveiro.

Tornava-se mister um movimento que acabasse com aquella vergonha social. A empresa não era facil e para ella se arregimentavam as mais bellas intelligencias e as mais decididas energias.

Travou-se, porfim, a peleja. [...] E aconteceu que naquelle dia 25 de março, para sempre memorável, o sol offuscante dos trópicos saudava a primeira terra brasileira onde todos eram livres, a qual um negro de genio [José do Patrocínio] por justos motivos cognominou - Terra da Luz (VALDEZ, 1984, p. 243-244). ${ }^{\text {a }}$

O Instituto do Ceará, como já foi destacado, seguiu as mesmas orientações do IHGB no final do século XIX, de priorização da coleta de documentos, que possuíam um caráter de verdade, sendo a história entendida como aquela dos grandes personagens e feitos que serviriam como exemplo. Em artigo da Revista intitulado "O Instituto e sua Revista", em 1925, Antonio Theodorico da Costa diz que:

Folheando a utilissima Revista, pagina por pagina, vê-se á luz de toda a evidencia, que ella é farta de documentos preciosos, bem mostrando o nosso passado e fallando dos principaes acontecimentos de que está repleta a nossa historia desde as mais longinquas datas.

[...] A nossa historia é bella.

Nella ha feitos grandiosos que nos elevam e nos honram.

Nas suas paginas ha brilhos que jamais se apagarão, muito embora o esquecimento e o olvido dos homens caia sobre elles como um peso esmagador.

Nesta Revista tudo se encontra mais ou menos para se poder formar a nossa historia.

[...] Temos também uma outra missão a desempenhar: - o nosso progredimento intellectual. Sem esses surtos da intelligencia não poderemos marchar com destinos certos e uma rota segura e luminosa para as conquistas da civilisação.

O Instituto é uma associação de lettras bem digna e bem util.

A Revista, que publica annualmente, é muito apreciada, não aqui no Ceará, onde conta somente com trinta e dois assignantes, e onde tambem as sociedades desse genero, na sua maioria, nascem e morrem sem nunca apresentar os fructos de seus labores, mas, nos paizes estrangeiros que se esforçam para obtel-a, como uma preciosíssima collectanea de documentação historica e trabalhos outros do maior realce literario.

[...] Felizmente os nossos governos teem auxiliado a publicação da Revista, de vez em quando, dotando-a com pequenas verbas para que ella continue no seu afanoso trabalho e assim possa contribuir para o esclarecimento dos principaes factos de nossa vida político-social (COSTA, 1925, p. 74, grifo nosso). ${ }^{\text {a }}$

Podemos ver, então, a ênfase numa história "bela", motivo de orgulho por seus "feitos grandiosos". Essa história deveria ser conhecida não apenas no Ceará, mas também pelo país e pelas demais nações ditas civilizadas. Em outro artigo sobre o Instituto, também de 1925, Eusébio Sousa esclarece como seria feito este trabalho:

Investigando o passado, rememorando as suas tradições, "arrancadas dos archivos do solo ou das pedras carcomidas dos monumentos", por intermedio desse "Instituto" dar-se-hia testemunho publico do quanto valia o Ceará, pois "nenhum dos 
Estados do Brasil tem como elle tamanha copia de documentos, mais vastos e seguros subsidios para a formação completa de sua historia especial" (SOUSA, 1925, p. 187, grifo nosso). ${ }^{\text {a }}$

Seria então através do passado e das tradições, dos documentos e dos monumentos que se compilaria a história do Ceará. A província possuía meios para isto, pois dispunha de número suficiente de documentos, bastava apenas que eles fossem investigados, selecionados e catalogados, trabalho que seria efetuado pelo Instituto do Ceará. Um trabalho de fortalecimento da identidade regional cearense a partir da memória de seus feitos, principalmente o de ter sido a primeira província do Brasil a libertar todos os seus escravos em 1884.

\section{Considerações Finais}

Para finalizar, reforçamos algumas ideias já apresentadas nos parágrafos introdutórios. Pensar a relação entre a escrita da história e a construção de identidade em diferentes regiões se faz relevante por seu potencial de ênfase nas particularidades, na multiplicidade de percepções de si mesmo diante de um todo nacional. Nesse sentido, olhar para o Ceará, o Instituto Histórico e seus intelectuais permite a descentralização dos estudos sobre historiografia brasileira. Conjugamos, assim, o geral ao específico, o regional ao nacional, o micro ao macro, de modo a, inclusive, dar espaço às lutas regionais, às questões simbólicas, de poder e profissionais que formam o campo intelectual e envolvem a construção de interpretações sobre uma província no processo de escrita da história nacional. Deste modo, no contexto aqui recortado, escreve história e é reconhecido quem tem poder e se projeta em meio às lutas políticas já mencionadas. O espaço de sociabilidade representado pelo Instituto do Ceará é emblemático no que se refere a esse trabalho de construção do regional relacionado ao nacional, conjugando história e memória na produção de uma leitura do passado que deveria gerar orgulho, identificação e unidade na primeira metade do século XX. O pioneirismo na abolição, a abnegação e a força diante do clima adverso seriam, a partir desse exercício, as principais características da identidade cearense com as quais ela se projetaria no cenário nacional. Uma intelectualidade atuante, articulada e bem inserida institucionalmente foi fundamental nesse processo, buscando-se, assim, subverter posições e romper estigmas que a condenavam ao atraso e a uma condição periférica. 


\section{Fontes}

\section{Periódicos:}

ABAIXO a escravidão. Libertador: Órgão da Sociedade Cearense Libertadora, Fortaleza, n. 2 , p. $1, \quad 15 \quad$ jan. $1881 . \quad$ Disponível em: http://memoria.bn.br/pdf/229865/per229865_1881_00002.pdf. Acesso em: 20 abr. 2018. ${ }^{\text {a }}$

ESTATUTOS do Instituto do Ceará. Revista Trimensal do Instituto do Ceará, Fortaleza, tomo I, p. 9-11, 1887. ${ }^{\text {a }}$

COSTA, Antonio Theodorico. O Instituto e sua Revista. Revista Trimensal do Instituto do Ceará, Fortaleza, t. 39, p. 69-75, 1925. Tipografia Minerva. ${ }^{a}$

SOUSA, Eusébio. Instituto do Ceará. Revista Trimensal do Instituto do Ceará, Fortaleza, t. 39, p. 178-202, 1925. Tipografia Minerva. ${ }^{a}$

VALDEZ, Alba. Uma data cearense. Revista do Instituto do Ceará, Fortaleza, t. esp. - $1^{0}$ Centenário da Abolição dos Escravos no Ceará, p. 243-244, 1984. Edições Universidade Federal do Ceará. ${ }^{a}$

\section{Referências}

ADERALDO, Mozart Soriano. Ele era um homem poliédrico. Tribuna do Ceará, 6 ago. 1988. Disponível em: http://www.raimundogirao.com.br/textos-sobre-girao/estudos-sobregirao/mozart-soriano-aderaldo. Acesso em: 15 jan. 2018. ${ }^{a}$

ALBUQUERQUE JUNIOR, Durval Muniz. A invenção do Nordeste e outras artes. São Paulo: Cortez, 2011. ${ }^{\mathrm{a}}$

ALONSO, Angela. Apropriação de Ideias no Segundo Reinado. In: GRINBERG, Keila; SALLES, Ricardo (Org.). O Brasil Imperial - 1870-1889. Rio de Janeiro: Civilização Brasileira, 2009. v. 3, p. 85-117. ${ }^{\text {a, b, c, d, e, f }}$

APRESENTAÇÃO - Obra. Raimundo Girão. @2011. Disponível em: http://www.raimundogirao.com.br/obra/apresentacao. Acesso em: 12 jan. 2018. ${ }^{a}$

BOURDIEU, Pierre. A identidade e a representação: elementos para uma reflexão crítica sobre a ideia de região. In: 1989. p. 107-132. a, b, c, d, e, f, g, h, i, j, k, l, m, n, o, p, q, r, s 
BOURDIEU, Pierre. A ilusão biográfica. In: FERREIRA, Marieta de Moraes; AMADO, Janaína (Org.). Usos e abusos da história oral. Rio de Janeiro: FGV, 2006. Arquivo Kindle, posição 2-5164. ${ }^{a}$

BOURDIEU, Pierre. Campo do poder, campo intelectual e habitus de classe. In: . $A$ economia das trocas simbólicas. São Paulo: Perspectivas, 2007. p. 183-202. a, b, c

CARDOSO, Gleudson Passos. As Repúblicas das letras cearenses: literatura, imprensa e política (1873-1904). 2000. 264 f. Dissertação (Mestrado)-Pontíficia Universidade Católica de São Paulo, São Paulo, 2000. ${ }^{a, b}$

CARDOSO, Gleudson Passos. Literatura, Imprensa e política (1873-1904). In: SOUZA, Simone; NEVES, Frederico de Castro (Org.). Intelectuais. Fortaleza: Demócrito Rocha, 2015. p. 41-71. , b, c $^{2}$

CHAVES JUNIOR, Eurípedes. GIRÃO, Valdelice Carneiro (Org). Raimundo Girão, o Homem (1900-2000). Fortaleza: Editores D’Aldeia, 2000. Edição Comemorativa do 1ํㅡㄴ centenário de nascimento de Raimundo Girão. ${ }^{a}$

GINZBURG, Carlo. História da Arte Italiana. In: GINZBURG, Carlo; CASTELNUOVO, Enrico; PONI, Carlo. (Org.). A micro-história e outros ensaios. Lisboa: Difel, 1989. p. 5-93. ${ }^{a}$

GIRÃO, Raimundo. A Abolição no Ceará. Fortaleza: A. Batista Fontenele, 1956.

GOMES, Angela de Castro. História e historiadores: a política cultural do Estado Novo. Rio de Janeiro: Fundação Getúlio Vargas, 2013. Arquivo Kindle, posição 643. ${ }^{a}$

MICELI, Sérgio. Intelectuais e classe dirigente no Brasil. In: . Intelectuais à brasileira. São Paulo: Companhia das Letras, 2001. p. 71-280. ${ }^{a, b, c, ~ d, ~} \bar{e}$

MACEDO, Joaryvar. Raimundo Girão - as Grandes Sínteses e o Apego ao Ceará. D. O. Letras, ano 111, n. 12, p. 1-5, jul./set. 1988. Disponível em: http://www.raimundogirao.com.br/textos-sobre-girao/estudos-sobre-girao/joaryvarmacedo. Acesso em: 14 jan. 2018. ${ }^{a}$

NOBRE, Geraldo da Silva. Vocação e Formação de um Historiador. D.O. Letras, ano 111, n. 12, p. 1-4, jul./set.1988. Disponível em: http://www.raimundogirao.com.br/textos-sobregirao/estudos-sobre-girao/geraldo-da-silva-nobre. Acesso em: 12 jan. 2018. ${ }^{a}$

OLIVEIRA, Almir Leal de. Universo letrado em Fortaleza na década de 1870. In: SOUZA, Simone; NEVES, Frederico de Castro (Org.). Intelectuais. Fortaleza: Demócrito Rocha, 2015. p. 15-39. a, b, c, d, e, f, g, h, i, j, k

POLLAK, Michael. Memória e Identidade Social. Estudos Históricos, Rio de Janeiro, v. 5, n. 10 , p. 200-212, 1992. ${ }^{a}$

SIRINELLI, Jean François. Os intelectuais. In: RÉMOND, René (Org.). Por uma História Política. Rio de Janeiro: FGV, 2003. p. 231-269. ${ }^{a}$ 
SOUZA, Simone; NEVES, Frederico de Castro (Org.). Introdução. In: Intelectuais. Fortaleza: Demócrito Rocha, 2015. p. 13-14. ${ }^{a, b}$

THIESSE, Anne-Marie. "La petite patrie enclose dans la grande": regionalismo e identidade nacional na França durante a Terceira República (1870-1940). Estudos Históricos, Rio de Janeiro, v. 8, n. 15, p. 3-16, 1995. a, b, d 